\title{
BMJ Open Guideline use behaviours and needs of primary care practitioners in China: a cross-sectional survey
}

\author{
Linan Zeng, ${ }^{1,2,3}$ Youping Li, ${ }^{2}$ Lingli Zhang, ${ }^{1,2,3}$ Guanjian Liu, ${ }^{2}$ Yang Zhang, ${ }^{1,3,4}$ \\ Shangwei Zhen, ${ }^{5}$ Honghao Li, ${ }^{5}$ Xue Song, ${ }^{4}$ Yanjun Duan, ${ }^{6}$ Jiajie Yu, ${ }^{2}$ \\ Xiaodong Wang ${ }^{5}$
}

To cite: Zeng L, Li Y, Zhang L, et al. Guideline use behaviours and needs of primary care practitioners in China: a crosssectional survey. BMJ Open 2017;7:e015379. doi:10.1136/ bmjopen-2016-015379

- Prepublication history and additional material are available. To view these files please visit the journal online (http://dx.doi org/10.1136/bmjopen-2016015379).

Received 5 December 2016 Revised 28 March 2017 Accepted 21 April 2017

\section{CrossMark}

1Department of Pharmacy/ Evidence-Based Pharmacy Center, West China Second University Hospital, Sichuan University, Chengdu, China ${ }^{2}$ Chinese Evidence-Based Medicine Centre/Chinese Cochrane Center, West China Hospital, Sichuan University, Chengdu, China

${ }^{3}$ Key Laboratory of Birth Defects and Related Diseases of Women and Children (Sichuan University), Ministry of Education, Chengdu, China

${ }^{4}$ West China school of Pharmacy, Sichuan University, Chengdu, China

${ }^{5}$ West China Hospital Institute of Management, Sichuan University, Chengdu, China

${ }^{6}$ College of Pharmacy, University of Nebraska Medical Center, Omaha, USA

Correspondence to

Dr Youping Li;

yzmylab@hotmail.com

\section{ABSTRACT}

Objectives Clinical guidelines have been recognised as an effective way to improve healthcare performance. However, little is known about the uptake and implementation of guidelines by general practitioners in China. The aim of this study was to investigate the guideline use behaviours and needs of practitioners in primary care settings in China.

Methods We conducted a cross-sectional survey from December 2015 to May 2016 that included practitioners at 268 institutions in 15 provinces in China. Questionnaire development was informed by the execution of a literature review and consultation of experts. On-site surveys were implemented using a paper questionnaire to minimise missing responses. A multivariate logistic regression analysis was performed to identify factors associated with provider knowledge of and attitudes towards clinical guidelines.

Results Of the respondents, $91.7 \%$ (1568/1708) were aware of clinical guidelines, but only $11.3 \%$ (177/1568) frequently used them. The main mechanism by which primary care practitioners accessed guidelines was public search engines (63.4\%; 911/1438), and practitioners seldom reported using biomedical databases. The most frequently identified barriers to guideline use were lack of training (49.9\%; 778/1560), lack of access (44.6\%; $696 / 1560)$ and lack of awareness (38.0\%; 592/1560). Less than one-quarter of respondents considered current guidelines 'entirely appropriate' for use in primary care (23.5\%; 339/1442). Most participants (96.2\%; $1509 / 1568$ ) believed it was necessary to develop primary care guidelines. Provider attitudes towards current guidelines were associated with the location and level of the institution and professional title of the practitioner $(p<0.05)$.

Conclusion Our survey revealed poor knowledge and uptake of clinical guidelines in primary care, and we identified a gap between the needs of practitioners and availability of clinical guidelines for use in primary care in China. In addition, lacking access to and training in guidelines also prevented primary healthcare practitioners from using guidelines in daily practice.

\section{INTRODUCTION}

Primary care is the cornerstone of essential healthcare and public health services in China,

\section{Strengths and limitations of this study}

- This study is the first survey of the behaviours, attitudes and needs related to clinical guidelines in Chinese primary care practitioners.

> Our findings shed light on the poor knowledge and uptake of clinical guidelines in primary care; additionally, a gap between the needs of practitioners and availability of guidelines for primary care in China was identified.

- Institutions and practitioners were not randomly selected during the sampling process.

and according to the China Health Statistics Yearbook, primary care is provided in $96 \%$ of all healthcare institutions and accounts for $60 \%$ of all healthcare visits. ${ }^{1}$ Having an effective primary care system is a prerequisite for improving access to healthcare services, reducing hospitalisations and enhancing equity. ${ }^{2-4}$ However, at present, primary care performance has been found to be poor and is plagued by low health human resource capacity, especially in rural areas of China. ${ }^{56}$ In light of the discrepancy between the low capacity and the high needs of primary care, the State Council has dedicated a substantial portion of China's New Health Reform to the improvement of primary care quality. ${ }^{7}$ In August 2016, President Xi noted that a prosperous society could not be achieved without addressing all aspects of health and promoted efforts towards universal coverage of high-quality medical services to the level of national strategy.

Clinical guidelines, which are defined by the Institute of Medicine as 'systematically developed statements to assist practitioner and patient decisions about appropriate health care for specific clinical circumstances,' are known as effective mechanisms by which to improve healthcare performance when an institution is equipped with sufficient medical 
resources and qualified staff. ${ }^{8-10}$ However, in China, little is known about the uptake and implementation of guidelines by general practitioners. More importantly, due to differences in governance, the health resources and staff available in primary care differ from those available in secondary and tertiary hospitals, and whether current guidelines are suitable for primary care use needs to be studied. Given these concerns, we undertook this descriptive cross-sectional survey study to gain a better understanding of general practitioners' attitudes towards and behaviours related to the implementation and uptake of clinical guidelines.

\section{METHODS}

Between December 2015 and May 2016, we implemented a cross-sectional survey of primary care practitioners' attitudes towards and behaviours related to clinical guidelines in China. We defined our respondents as practitioners from county hospitals and grass-roots institutions, including community health centres, health centres in villages and towns, and clinics. ${ }^{11}$

\section{Survey sites and sampling}

Institutions and practitioners were not randomly selected during the sample process due to the unavailability of national registries. To obtain a representative sample, we selected five provinces from Eastern (Beijing, Guangdong, Fujian, Shandong and Zhejiang), Central (Heilongjiang, Hubei, Hunan, Jilin and Shanxi) and Western China (Sichuan, Shanxi, Yunnan, Xinjiang and Xizang) that were representative of the population density, economic development and medical services of their respective regions, respectively. In each selected province, we contacted one to three tertiary level hospitals through the International Network for Rational Use of Drugs (INRUD), China. These tertiary level hospitals carried out the survey in five county hospitals and five grass-roots institutions within their province. Three ten-thousandth $(0.3 \%)$ of all primary care institutions (912 620) in China were included in our survey. In each county hospital, three physicians, three nurses, three administrative staff and three practitioners from auxiliary departments, including the pharmacy, laboratory, radiology and ultrasonography departments, were randomly selected to complete the questionnaire. In each grass-roots institution, two to five health practitioners were randomly selected to complete the survey according to the total number of institutional practitioners regardless of specialty.

\section{Survey tool}

Questionnaire development was informed by the execution of a literature review and consultation with experts; additionally, the questionnaire was revised based on feedback from a pretest performed in two primary care institutions in the Sichuan and Xizang provinces. ${ }^{9}$ The questionnaire consisted of the following sections: (1) demographic characteristics of primary care practitioners; (2) primary care practitioners' knowledge and implementation of clinical guidelines; and (3) primary care practitioners' attitudes towards primary care-specific clinical guidelines (see online supplementary appendix $1)$. Knowledge of clinical guidelines was divided into the following three levels: completely knowledgeable, partially knowledgeable and unaware. If the general practitioner responded that he or she did not know what clinical guidelines were or had never used clinical guidelines, the survey was stopped in the second section. Multiple-choice questions were asked to allow respondents to describe the frequency, sources, preferred types of and barriers to guidelines. The degree that current guidelines were applicable to primary care practice was divided into four levels: entirely applicable, partially applicable, inapplicable and unaware. If the general practitioner responded that he or she did not think it was necessary to develop clinical guidelines for primary care, the survey was stopped in the third section. The characteristics of institutions were also investigated using a universal form (see online supplementary appendix 2 ). The language of the survey was Chinese.

\section{Survey procedures}

To help minimise the possibility of a methodology bias existing across provinces, the same questionnaire and a consistent survey framework were used to ensure the overall comparability of results. ${ }^{12-14}$ All investigators were trained by the chief investigator (Linan Zeng) and sent to primary care institutions to perform on-site surveys using paper questionnaires to minimise missing responses. The surveys were carried out anonymously.

\section{Ethical review}

Ethical approval was obtained from the Ethics Committee of West China Second University Hospital in May 2015. Written informed consent was deemed to be unnecessary, as the study only investigated practitioners' attitudes towards and behaviours related to clinical guidelines, and data were collected anonymously.

\section{Statistical analysis}

Data were entered into a Microsoft Excel spreadsheet designed for the study, and data entry was audited by randomly selecting $10 \%$ of the electronic questionnaires and comparing the responses with those on the hard copies. Questionnaires with missing data were included in the analysis, but the missing answers were excluded from the calculations.

We used simple descriptive statistics to summarise the data from the survey. Categorical variables are expressed as proportions, and their significance was assessed using the Wilcoxon rank-sum test or Kruskal-Wallis (K-W) rank-sum test when appropriate. Continuous variables are expressed as means and SD, or medians and IQRs. We performed binary logistic regression analyses to identify factors associated with knowledge of and 
attitudes towards clinical guidelines after combining the dependent variables into two categories. The explanatory variables used in the multivariate logistic regression analysis were the level and region of the institutions and the professional title, profession and educational background of the practitioners. Statistical analyses were performed using SPSS V.16.0 software, and 95\% CIs were calculated. A two-sided $p$ value of $\leq 0.05$ was considered statistically significant.

\section{RESULTS}

Within the included 268 institutions, 1308 and 620 health practitioners from county hospitals and grass-roots institutions were enrolled in the survey, respectively. Of these practitioners, 1708 completed the entire questionnaire, for a response rate of $88.6 \%$. The most frequently cited reason for non-response was other duties (eg, seeing patients). The questionnaire was most frequently completed via face-to-face survey $(84.0 \% ; 1433 / 1708)$, except for in a few rural areas where email or telephone surveys were used.

Fifty-seven per cent of the institutions (155/268) provided institutional characteristic data (table 1). The median service radius was $10 \mathrm{~km}$, and their coverage reached approximately 70000 patients. The majority of the physicians and nurses who played major roles in the provision of primary care were college graduates with primary or intermediate professional titles. With regard to the institutions' techniques and facilities, most institutions were capable of performing routine blood tests, hepatic and renal function examinations, and so on. However, techniques such as bacterial culture, therapeutic drug monitoring and MRI were still not universally available at the grass-roots level. Staffing, medical services, techniques and facilities were similar across the different regions.

Of the 1708 respondents, most had a bachelor's degree or lower $(97.5 \% ; 1665 / 1708)$ and an immediate professional title or lower $(81.9 \%$; 1399/1708), which was consistent with the overall staffing situation in primary care institutions. More than one-third of respondents $(35.6 \%)$ were physicians, while nurses, practitioners from auxiliary departments and administrative personnel each accounted for $20 \%$ of the overall study population, which was in accordance with the professional distribution of guideline users in China (table 2). ${ }^{15}$

\section{Knowledge of clinical guidelines}

The majority of healthcare providers were 'completely' or 'partially' knowledgeable about clinical guidelines (91.7\%; 1568/1708). One hundred and forty-two (8.3\%) providers reported that they knew nothing about guidelines, $71.1 \%(101 / 142)$ of whom had a primary or no professional title (table 3). Practitioners with higher professional titles tended to be more knowledgeable about guidelines (K-W H=195.102, $\mathrm{p}<0.001$ ). Similarly, a positive correlation between education level and awareness of guidelines was identified ( $\mathrm{K}-\mathrm{W} \mathrm{H}=97.125, \mathrm{p}<0.001$ ). Among the evaluated practitioners, those from auxiliary departments most frequently reported 'completely understanding' guidelines $(50.3 \% ; 186 / 370)$, while physicians most frequently reported being 'fully unaware of guidelines', which indicated the presence of insufficient understanding in and use of clinical guidelines by primary care providers $(10.0 \%$; 61/610) (K-W H=19.041; $\mathrm{p}<0.001)$.

\section{Behaviours regarding clinical guidelines}

Of the 1588 practitioners who were knowledgeable about clinical guidelines, only $11.3 \%(177 / 1568)$ frequently used these guidelines, and the majority reported only occasionally using them $(45.2 \%$; 709/1568). Moreover, $8.0 \%(126 / 1568)$ of the practitioners had never used clinical guides even though they were aware of them. The modalities by which primary care practitioners most frequently accessed clinical guidelines were as follows: public search engines (63.4\%; 911/1438), medical websites $(48.5 \%$; 697/1438) and information distributed by institutions $(40.0 \% ; 575 / 1438)$, and biomedical databases were infrequently reported to be sources of clinical guidelines. Moreover, 3.6\% (52/1438) reported being completely unaware of how to obtain guidelines. Although few in number, primary care-specific clinical guidelines remained the first choice for primary care practitioners in China $(72.1 \% ; 1024 / 1420)$ (table 4). ${ }^{16}$

The three main barriers cited by practitioners as preventing guideline use were lack of training (49.9\%; $778 / 1560)$, lack of access $(44.6 \%$; 696/1560) and lack of awareness $(38.0 \%$; 592/1560). In addition, guideline-related issues that were cited as preventing guideline use included delayed updates $(35.8 \%$; 559/1560), redundant formats (33.7\%; 525/1560), guidelines deemed impractical for use in primary care $(30.6 \% ; 477 / 1560)$ and language barriers associated with English guidelines $(16.2 \% ; 252 / 1560)$ (table 4).

\section{Attitudes towards current clinical guidelines}

Less than one-quarter of respondents considered current guidelines to be 'entirely applicable' within the primary care setting (23.5\%; 339/1442). Instead, the majority $(71.4 \% ; 1030 / 1442)$ believed they were "partially applicable'. The degree to which practitioners perceived current guidelines to be applicable to primary care was similar regardless of profession, professional title or education level (table 5) (K-W H=4.982, $\mathrm{p}=0.173$; K-W $\mathrm{H}=3.228, \mathrm{p}=0.199$; K-W H=0.460, p=0.795, respectively).

\section{Attitudes towards clinical guidelines and needs of primary care practitioners}

Most participants $(96.2 \%$; 1509/1568) reported the necessity of developing clinical guidelines for primary care institutions, and the responses to this question did not differ by profession, professional title or education level (K-W H=1.308, $\mathrm{p}=0.727$; K-W H=0.542, $\mathrm{p}=0.763$; $\mathrm{K}-\mathrm{W}$ $\mathrm{H}=0.329, \mathrm{p}=0.848$, respectively). Ten of the 39 respondents who believed clinical guidelines to be 'unnecessary' 


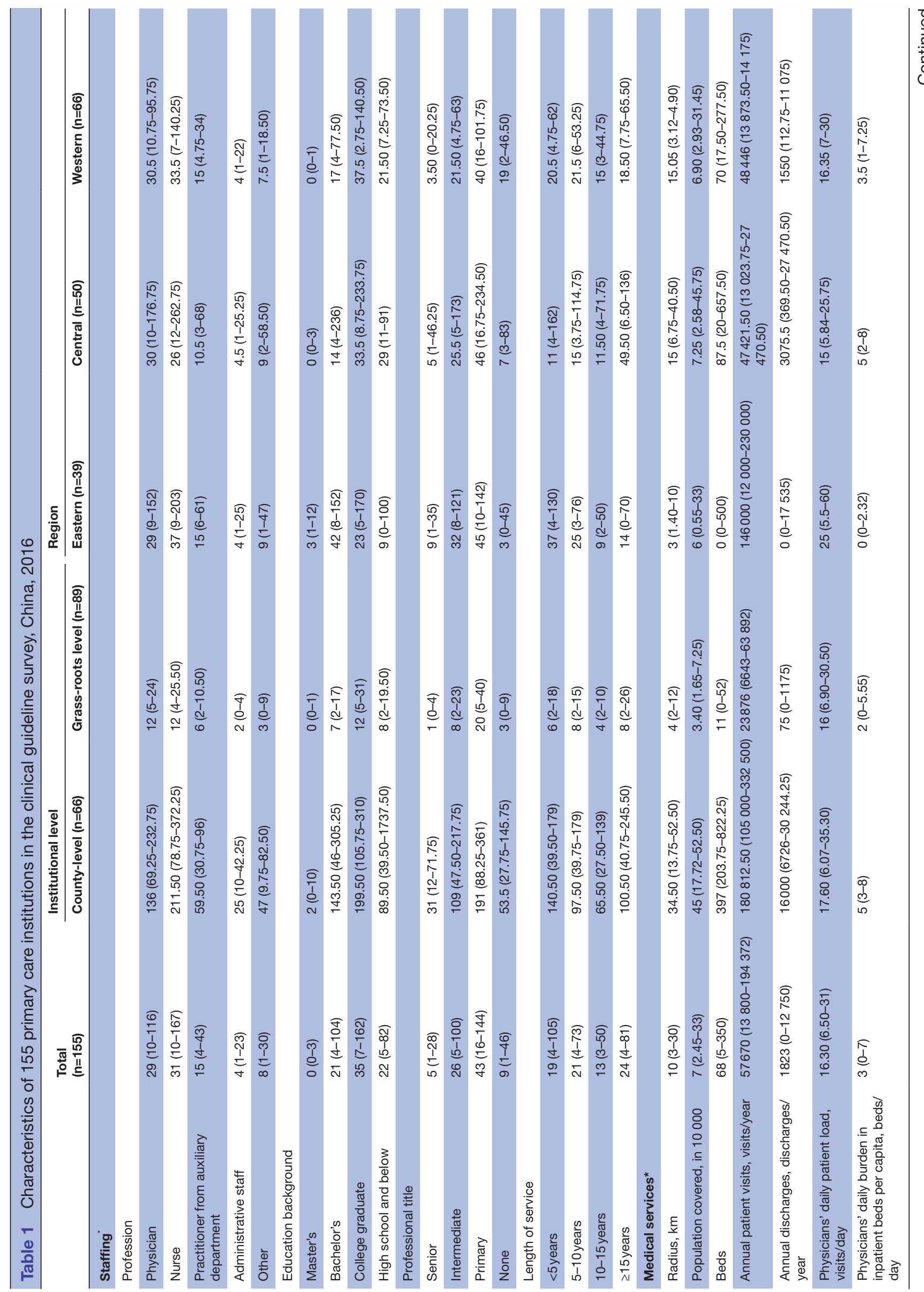




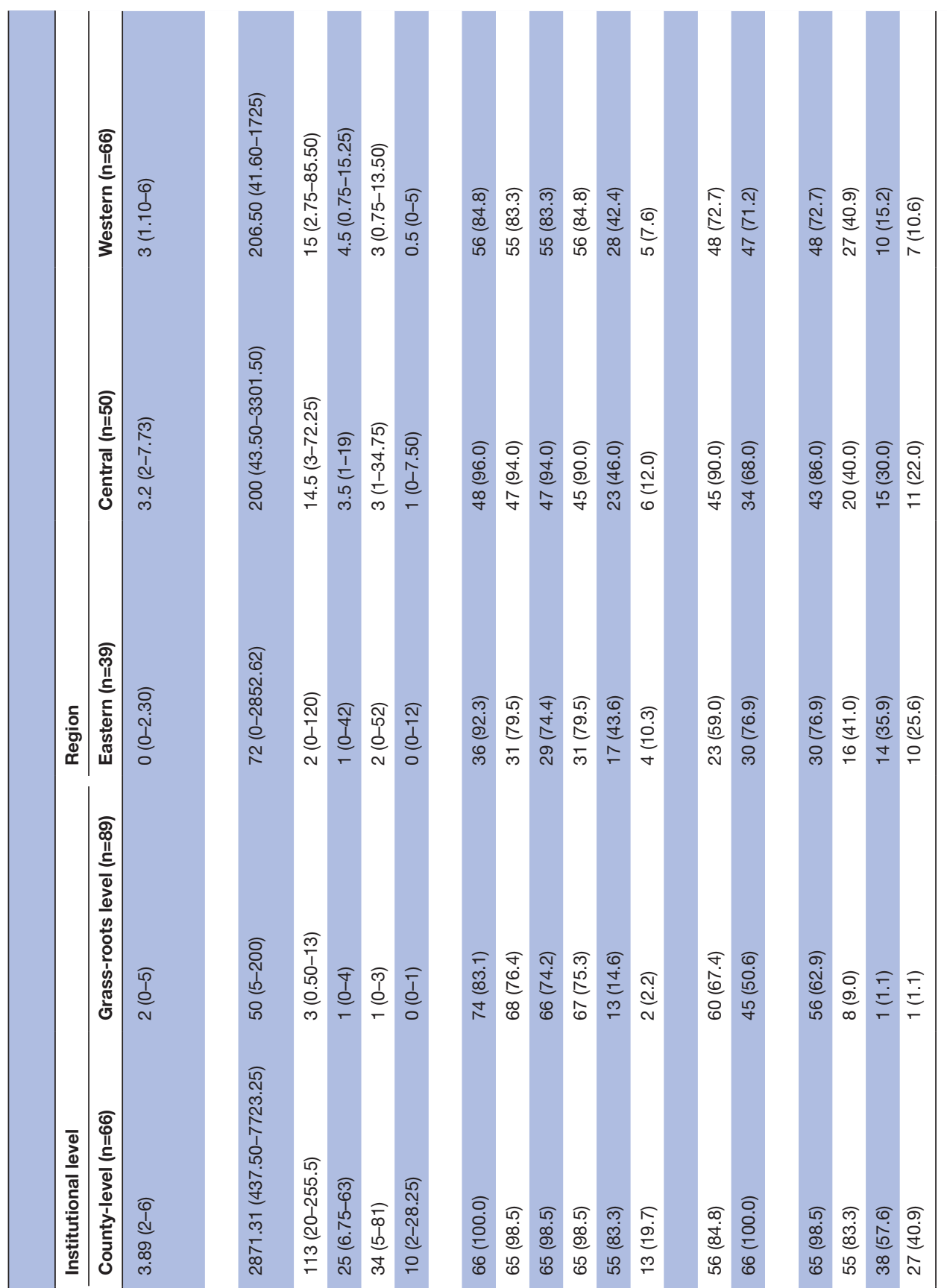

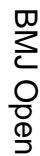
王

$\stackrel{\underline{\varphi}}{\risingdotseq}$

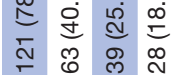

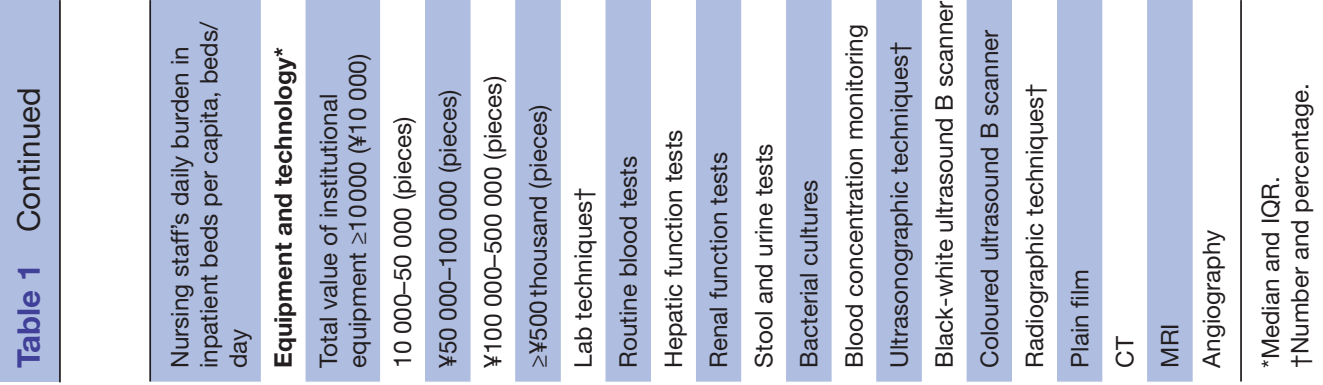


Table 2 Professional and demographic characteristics of the 1708 primary care health practitioners participating in the clinical guideline survey, China, 2016

\begin{tabular}{|c|c|c|c|c|c|c|}
\hline \multirow[b]{3}{*}{ Characteristics } & \multicolumn{6}{|l|}{ N (\%) } \\
\hline & \multirow[b]{2}{*}{ Total $(n=1708)$} & \multicolumn{2}{|c|}{ Institutional level } & \multicolumn{3}{|c|}{ Geographical area } \\
\hline & & $\begin{array}{l}\text { County } \\
(n=1088)\end{array}$ & $\begin{array}{l}\text { Grass-roots } \\
\text { level }(n=620)\end{array}$ & $\begin{array}{l}\text { Eastern } \\
(n=350)\end{array}$ & $\begin{array}{l}\text { Central } \\
(n=536)\end{array}$ & $\begin{array}{l}\text { Western } \\
(\mathrm{n}=822)\end{array}$ \\
\hline \multicolumn{7}{|l|}{ Education } \\
\hline Master's, doctorate & $43(2.5)$ & $25(2.3)$ & $18(2.9)$ & $15(4.3)$ & $15(2.8)$ & $13(1.6)$ \\
\hline Bachelor's & $958(56.1)$ & $682(62.7)$ & $276(44.5)$ & $214(61.1)$ & 302 (56.3) & $442(53.8)$ \\
\hline College and below & 707 (41.4) & $381(35.0)$ & 326 (52.6) & $121(34.6)$ & 219 (40.9) & 367 (44.6) \\
\hline \multicolumn{7}{|l|}{ Professional title } \\
\hline Senior & $309(18.1)$ & $252(23.2)$ & 57 (9.2) & $63(18.0)$ & $101(18.8)$ & 145 (17.6) \\
\hline Intermediate & $613(35.9)$ & 402 (36.9) & $211(34.0)$ & $119(34.0)$ & 203 (37.9) & $291(35.4)$ \\
\hline Primary and below & $786(46.0)$ & 434 (39.9) & $352(56.8)$ & $168(48.0)$ & $232(43.4)$ & $386(47.0)$ \\
\hline \multicolumn{7}{|l|}{ Profession } \\
\hline Physician & $610(35.7)$ & $315(29.0)$ & 295 (47.6) & $121(34.6)$ & $173(32.3)$ & $315(38.4)$ \\
\hline Nurse & $411(24.1)$ & $263(24.2)$ & 148 (23.9) & $90(25.7)$ & $131(24.4)$ & $190(23.1)$ \\
\hline $\begin{array}{l}\text { Practitioner from auxiliary } \\
\text { department }\end{array}$ & $370(21.7)$ & $262(24.1)$ & $108(17.4)$ & $82(23.4)$ & $116(21.6)$ & $172(20.9)$ \\
\hline Administrative staff & 317 (18.6) & $248(22.8)$ & $69(11.1)$ & 57 (16.3) & $116(21.86)$ & $144(17.5)$ \\
\hline
\end{tabular}

reported the following reasons for this belief: (1) primary care practitioners should use the same guidelines as other practitioners to remain current on updated clinical recommendations; (2) the lack of access could not be remedied by simply developing new guidelines; and (3) lack of time to review guidelines. Among the 20 respondents who reported they 'do not care' about primary care guideline development, five explained their reasons for this belief: (1) the provider did not use guidelines in their daily work; and (2) the clinical guidelines were too specific for primary care practitioners, as they usually address general diseases (table 5).

As for the preferred clinical guidelines, more than half of the participants tended to use full guideline versions (56.5\%; $874 / 1546$ ), while $15.2 \%$ accepted both full and summary versions. For language, most practitioners preferred Chinese $(96.8 \% ; 1496 / 1546)$. More than half of the practitioners believed hard copies of guidelines would be more appropriate in primary care $(51.5 \%$; $797 / 1546)$, while $35.8 \%$ (53/1546) embraced both paper and electronic versions. Regarding guideline content, requests for specialised and general guidelines were voiced almost equally $(58.0 \%$ and $42.0 \%$, respectively). Healthcare providers at the county level $(33.4 \%$; 329/986) reported having a significantly greater need for specialised guidelines than did grass-roots level providers $(45.0 \%$; 252/560; $\mathrm{Z}=-4.538 ; \mathrm{p}<0.001)$. The top three preferred modalities by which to access guidelines were public search engines $(45.6 \% ; 703 / 1541)$, distributed periodicals $(43.4 \%$; 669/1541) and medical websites $(42.6 \%$; $657 / 1541)$, a finding that was in accordance with the practitioners' guideline searching habits. Ninety-one per cent of the participants $(1409 / 154)$ welcomed training regarding the application of guidelines in primary care settings.

\section{Multivariate logistic regression}

Knowledge about clinical guidelines was positively associated with education level and professional title $(p<0.001)$, as well as profession and geographical area. Compared with administrative staff, physicians and nurse practitioners were less likely to report being 'completely knowledgeable' about clinical guidelines $(\mathrm{OR}=0.636, \mathrm{p}=0.004$; $\mathrm{OR}=0.614, \mathrm{p}=0.001$ ). The odds of being 'completely knowledgeable' was lower in practitioners in central China than those in western China $(\mathrm{OR}=0.648, \mathrm{p}<0.001)$.

Attitudes towards the current guidelines were associated with the location and level of the institution and professional title of the practitioner. Western practitioners were more likely to report that clinical guidelines were 'not entirely appropriate' than were central practitioners $(\mathrm{OR}=0.399, \mathrm{p}=0.017)$. Providers working in grass-roots settings were at greater odds of believing that guidelines were 'not entirely appropriate' than were county-level hospital providers $(\mathrm{OR}=1.315, \mathrm{p}=0.045)$. A greater proportion of participants with intermediate and senior titles believed clinical guidelines to be "not entirely appropriate' relative to those with primary titles $(\mathrm{OR}=0.356, \mathrm{p}=0.031 ; \mathrm{OR}=1.602, \mathrm{p}=0.009) \quad($ table 6$)$.

\section{DISCUSSION}

\section{Findings of this survey}

This study is the first to examine primary care providers' behaviours, attitudes and needs related to clinical guidelines in China. Our data suggest that the surveyed Chinese primary care practitioners lacked knowledge about clinical guidelines. Of those completely unaware of clinical guidelines, $4.2 \%$ reported having a senior title. 
Table 4 Behaviours related to clinical guideline use in 1568 primary care health practitioners, China, 2016

Guideline utilisation N (\%)

Frequency of guideline use $(n=1568)^{*}$

Frequently $177(11.3)$

Often $556(35.5)$

Occasionally 709 (45.2)

Never $126(8.0)$

Sum $1568(100.0)$

Sources of guidelines $(n=1438)$

Public search engines $911(63.4)$

Medical websites $697(48.5)$

Materials distributed by institutions $\quad 575$ (40.0)

Professional academic journals $\quad 413(28.7)$

Chinese biomedical databases $408(28.4)$

Materials distributed by companies $188(13.1)$

Foreign biomedical databases $69(4.8)$

Unaware of how to obtain guidelines $52(3.6)$

Preferred types of guidelines $(n=1420)^{1}$

Chinese guidelines for primary care institutions

Chinese guidelines for all medical institutions 1006 (70.9)

Translated foreign guidelines (Chinese 261 (18.4) versions)

Original foreign guidelines (English versions)

$66(4.6)$

Barriers to guideline use $(n=1560)$

Lack of training $778(49.9)$

Lack of access $696(44.6)$

Lack of awareness $592(38.0)$

Guidelines not updated in a timely manner 559 (35.8)

Guidelines not sufficiently concise $525(33.7)$

Limited practitioner knowledge $480(30.8)$ Guidelines not practical for implementation 477 (30.6) at the grass-roots level

$\begin{array}{lc}\begin{array}{l}\text { Lack of oversight mechanisms to ensure } \\ \text { medical practice fulfils the clinical } \\ \text { recommendations }\end{array} & 329(21.1) \\ \text { Language barriers } & 252(16.2) \\ \text { Lack of time to review guidelines } & 227(14.6) \\ \text { Others } & 5(0.3)\end{array}$

*'Frequently' was defined as using guidelines on a daily basis. 'Often' was defined as using guidelines on a weekly basis.

'Occasionally' was defined as using guidelines on a monthly basis.

Ten per cent of the clinical physicians were unaware of clinical guidelines, and even higher proportions of medical technicians, nursing and administrative staff reported being unaware. Clinical guideline usage was not common in primary care institutions. Eight per cent of medical staff reported having never used guidelines. Most primary care staff reported accessing guidelines through 
resources other than professional biomedical databases $(63.4 \%)$. Knowledge and use of guidelines were higher in those who reported higher educational and professional levels. The following factors were identified as obstacles to guideline use: limitations of the guidelines themselves, insufficient access to and training regarding guidelines, limited medical staff knowledge, and inadequate awareness of guideline use. Despite the presence of insufficient knowledge and guideline use in primary care, $98.5 \%$ of the medical staff still believed that clinical guidelines are needed in primary care institutions. Nearly all practitioners expressed a desire to learn about or improve their guideline-based practice skills $(91.1 \%)$, which indicates the need for clinical guideline development in primary care institutions in China. Most primary care practitioners suggested that clinical guidelines should be developed for primary care $(96.2 \%)$ and supported the provision of guideline training $(91.1 \%)$.

\section{Comparison with similar studies}

The results of a survey of knowledge and attitudes related to clinical guidelines among primary practitioners that was conducted in Gansu province in China suggested that while $80 \%$ of respondents $(114 / 143)$ were aware of these guidelines, only $51 \%$ used them in daily practice. ${ }^{17}$ In that study, $37 \%$ of the participants believed that lacking guideline access was a major barrier to guideline use $(53 / 143)$, and $88 \%$ of the participants stated that they needed guideline training (126/143). ${ }^{17}$ These results are consistent with those of our study. Similarly, a cross-sectional survey conducted in western Sweden showed that 96\% of primary care practitioners considered guidelines to be important, but only one-third of these providers reported being aware of guidelines; barriers cited in that study included lack of time and unavailability of and limited access to guidelines. ${ }^{18}$ A study conducted in Germany showed that despite the popularity of chronic obstructive pulmonary disease (COPD) guidelines, differences in health resource and medical staffing conditions between primary care and tertiary hospitals resulted in the persistence of deficits between pneumologists and primary care practitioners regarding the diagnosis and treatment of COPD and practical implementation of educational measures. ${ }^{19}$ A qualitative descriptive study conducted in Canada explored the facilitators of and barriers to guideline use among physicians and focused on the application of the Grading of Recommendations Assessment, Development and Evaluation (GRADE) method for guideline development. The results of this survey suggested that the interviewees recognised the need for guidelines and the benefits of using the GRADE method during the guideline development process. ${ }^{20}$

Characteristics of Chinese primary care system and status of primary care clinical guidelines in China

The major responsibilities of Chinese primary care providers are to prevent, diagnose, and treat common diseases and provide public health services, including 


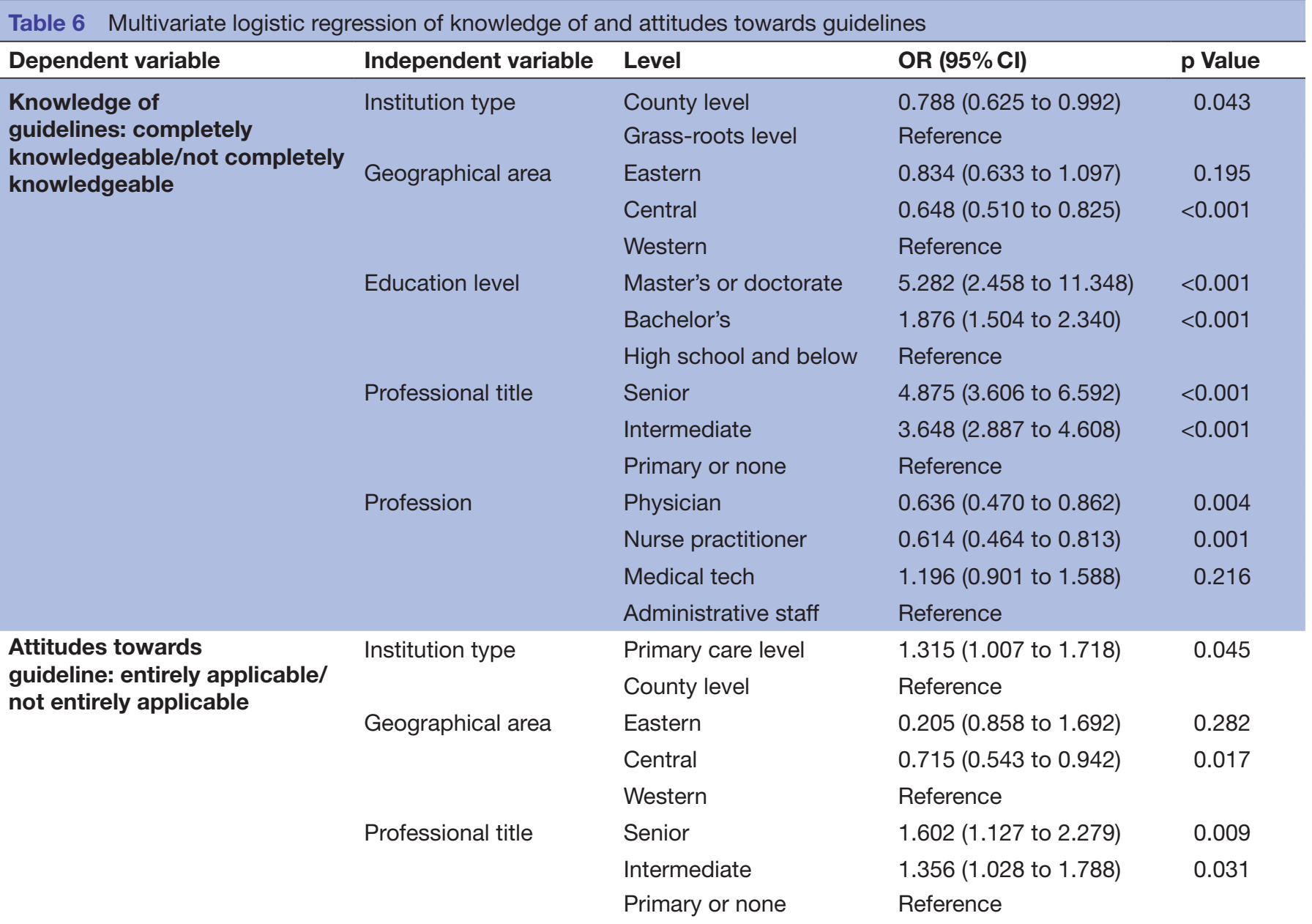

health education and consulting, chronic disease management and rehabilitation services. The medical reforms launched in China in 2009 aimed to strengthen the primary healthcare system. ${ }^{21}$ However, despite several years of primary care reform, the current performance of the Chinese primary healthcare system remains poor. ${ }^{6}$ In addition, regional disparities exist in medical service ability, and the quality of primary healthcare in western China remains weaker than that of eastern and central China. $^{22}$

Clinical guideline may serve as an important mechanism by which to improve medical service quality and promote health service equity. ${ }^{823}$ However, the lack of appropriate clinical guidelines for primary care may seriously impact the overall quality of medical care in China. Among the five most common chronic diseases in China (hypertension, diabetes, cancer, stroke and COPD), primary care-specific guidelines are only available for hypertension and diabetes. ${ }^{24} 25$ Moreover, a quality assessment of current primary care-specific guidelines showed that although they were more readable than normal guidelines, many quality problems were identified, including poor precision, the absence of review by external experts and a lack of primary care staff participation. ${ }^{16}$ In contrast, some studies have reported that guidelines that were more suitable for primary care were associated with improved health outcomes and strengthened the health system. ${ }^{26} 27$

\section{Strengths and limitations}

Response bias

We did not randomly select the included institutions and practitioners because the national registries of both primary care institutions and health practitioners were not available. However, we balanced the number of selected institutions across provinces and covered all levels and the majority of professions in primary care. In addition, the questionnaires were distributed and completed via faceto-face interviews, except for in a few rural areas. Therefore, these data can be considered to be representative. Nevertheless, for questions that respondents may have felt required to provide a 'correct' response, a bias may have resulted from respondents providing the answer they felt was 'expected'. Moreover, on this closed-ended quantitative survey questionnaire, the researcher could not probe further into the respondents' answers or explore their levels of understanding and intent. In addition, $11.4 \%$ of potential respondents failed to complete the questionnaire. Knowledge and uptake of guidelines in this population may be poorer. Although this survey can provide a snapshot of the current situation in primary care, additional qualitative research is necessary to generate a more 
comprehensive understanding of needs related to clinical guidelines in primary care in China.

\section{CONCLUSION}

Our findings shed light on the poor knowledge levels and infrequent use of clinical guidelines in primary care. Additionally, a gap between the needs of practitioners and the availability of guidelines for primary care in China was identified. In addition, lack of access to and training related to guidelines may also prevent primary healthcare workers from using guidelines in daily practice.

Contributors Linan Zeng, Youping Li and Lingli Zhang were responsible for conception and design. Linan Zeng, Yang Zhang, Shangwei Zhen, Honghao Li and Xiaodong Wang collected the data. Guanjian Lu, Xue Song and Jianjie Yu analysed and interpreted data. Linan Zeng, Youping Li, Lingli Zhang and Yanjun Duan drafted and revised the paper.

Competing interests None declared.

Patient consent Patient.

Ethics approval West China Second University Hospital.

Provenance and peer review Not commissioned; externally peer reviewed.

Data sharing statement No additional data are available.

Open Access This is an Open Access article distributed in accordance with the Creative Commons Attribution Non Commercial (CC BY-NC 4.0) license, which permits others to distribute, remix, adapt, build upon this work non-commercially, and license their derivative works on different terms, provided the original work is properly cited and the use is non-commercial. See: http://creativecommons.org/ licenses/by-nc/4.0/

(C) Article author(s) (or their employer(s) unless otherwise stated in the text of the article) 2017. All rights reserved. No commercial use is permitted unless otherwise expressly granted.

\section{REFERENCES}

1. National Health and Family Planning Commission of the PRC. China health statistics yearbook 2013 http://www.nhfpc.gov.cn/htmlfiles/ zwgkzt/ptjnj/year2013/index2013.html (Accessed September 1, 2016).

2. Phillips RL, Han M, Petterson SM, et al. Cost, utilization, and quality of care: an evaluation of illinois' medicaid primary care case management program. Ann Fam Med 2014;12:408-17.

3. Mark DH, Gottlieb MS, Zellner BB, et al. Medicare costs in urban areas and the supply of primary care physicians. J Fam Pract 1996;43:33-9.

4. Li H, Chung RY, Wei X, et al. Comparison of perceived quality amongst migrant and local patients using primary health care delivered by community health centres in Shenzhen, China. BMC Fam Pract 2014;15:76.

5. Tang S, Meng Q, Chen L, et al. Tackling the challenges to health equity in China. The Lancet 2008;372:1493-501.

6. Bhattacharyya O, Delu $\mathrm{Y}$, Wong ST, et al. Evolution of primary care in China 1997-2009. Health Policy 2011;100(2-3):174-80.

7. People.com.cn - the People's Daily. Mr. Li: health care work center focused on guaranteeing the basic, strengthening the base, and establishing a mechanism 2010 http://qh.people.com.cn/GB/ 11675839.html (Accessed September 1, 2016).

8. Woolf SH, Grol R, Hutchinson A, et al. Clinical guidelines: potential benefits, limitations, and harms of clinical guidelines. BMJ 1999;318:527-30.

9. Siriwardena AN. Clinical guidelines in primary care: a survey of general practitioners' attitudes and behaviour. Br J Gen Pract 1995;45:643-7.

10. Molyneux E, Weber MW. Applying the right standards to improve hospital performance in Africa. Lancet 2004;364:1560-1.

11. National Health and Family Planning Commission of the PRC. The notice on strengthening supervision on the grass-roots medical institutions 2012 http://www.nhfpc.gov.cn/zwgkzt/s9968/201205/ 54898.shtml (Accessed September 1, 2016).

12. Krosnick JA. A New introduction to survey methods. Psyccritiques 1994;39:221-2.

13. Haslinger-Baumann E, Lang G, Müller G, et al. Validity and reliability of the "German Utilization Questionnaire-Dissemination and Use of Research" to measure attitude, availability, and support toward implementation of research in nursing practice. $J$ Nurs Meas 2014:22:255-67.

14. Ide T, Sata M, Sakisaka S, Tatsuya I, Michio S, et al. Peginterferonalpha-2b plus Ribavirin therapy in patients with chronic hepatitis $C$ as assessed by a multi-institutional questionnaire in Japan. Hepatol Res 2010;40:557-65.

15. Mj W, Zhang SJ, Zhou ZC, et al. Use and demand of clinical practice guidelines in China. Chin J Med Libr Inf Sci 2016;25:37-42.

16. Tang YC, Shen G, SI H, et al. Analysis and evaluation of China's clinical guidelines for management of chronic disease in primary clinics. Chinese Journal of Hypertension 2013;21(1):48-52.

17. Chen YL, Yao L, Wang Q, et al. Survey on knowledge, attitude and behavior regarding clinical practice guidelines of primary care workers in Gaolan County of Gansu Province. Chin J Evid-based Med 2014;14(6):674-7.

18. Bernhardsson S, Johansson K, Nilsen P, et al. Determinants of guideline use in primary care physical therapy: a crosssectional survey of attitudes, knowledge, and behavior. Phys Ther 2014;94:343-54

19. Glaab T, Banik N, Rutschmann OT, Olivier TR, et al. National survey of guideline-compliant COPD management among pneumologists and primary care physicians. COPD 2006;3:1541-2555.

20. Alexander PE, Li SA, Tonelli M, et al. Canadian primary care Physicians' Attitudes toward understanding clinical Practice guidelines for Diabetes Screening. Can J Diabetes 2016;40:580-5.

21 The State Council of China, Instructional advice on building general practional system by the State Council.2011. Available from: http:// www.gov.cn/zwgk/2011-07/07/content_1901099.htm (Accessed May 29, 2015).

22. Wang $M$, Fang $\mathrm{H}$, Bishwajit $\mathrm{G}$, et al. Evaluation of rural primary Health Care in Western China: a Cross-Sectional Study. Int J Environ Res Public Health 2015;12:13843-60.

23. Lenzer J, Hoffman JR, Furberg CD, et al. Ensuring the integrity of clinical practice guidelines: a tool for protecting patients. BMJ 2013;347:f5535.

24. China hypertension management manual revision committee at the grass-roots level.China's high blood pressure at the grass-roots level management guidelines (revised in 2014). Chinese Journal of Health Management 2015;9:10-33.

25. Society CD. Chinese type 2 diabetes prevention guide (primary). Chinese Journal of General Practitioners 2013;12:675-96 http:// zhqkys.cma.org.cn/CN114798201308/598326.htm

26. Fairall LR, Zwarenstein M, Bateman ED, et al. Effect of educational outreach to nurses on tuberculosis case detection and primary care of respiratory illness: pragmatic cluster randomised controlled trial. BMJ 2005;331:750-4.

27. Zwarenstein M, Fairall LR, Lombard C, et al. Outreach education for integration of HIV/AIDS care, antiretroviral treatment, and tuberculosis care in primary care clinics in South Africa: palsa PLUS pragmatic cluster randomised trial. BMJ 2011;342:d2022. 